\title{
LUTAS E RESISTÊNCIAS DE UMA PROFESSORA AO EXERCÍCIO DO MAGISTÉRIO NA ESCOLA JOSÉ DE ALENCAR -1982
}

\author{
STRUGGLES AND RESISTANCE STUMUITIES OF A TEACHER TO THE EXERCISE OF \\ TEACHING AT JOSÉ DE ALENCAR SCHOOL -1982
}

\section{LUCHAS Y ESTUMUIDADES DE RESISTENCIA DE UN PROFESOR AL EJERCICIO DE LA DOCENCIA EN EL COLEGIO JOSE DE ALENCAR -1982}

\author{
Maria Clelia Pereira da Costa ${ }^{1}$
}

\begin{abstract}
Resumo: O objetivo desse artigo é dar visibilidade à história de vida das professoras Ordalha e Marlene, a partir do conceito de "infâmia" tratado por Michel Foucualt e de pesquisa qualitativa por entrevistas realizadas em 2015. Os resultados apontam um legado que merece ser conhecido pelas novas gerações de professores.
\end{abstract}

Palavras-chave: Resistência ao magistério; experiência de vida; estudos foucaultianos.

\begin{abstract}
The aim of this article is to give visibility to the life history of teachers Ordalha and Marlene, from the "infamy" treated by Michel Foucault. Qualitative research with interviews conducted in 2015 . The results point to a legacy that deserves to be known by the new generations of teachers.
\end{abstract}

Keywords: Resistance to teaching; life experience; foucaultian studies.

Resumen: El objetivo de este artículo es dar visibilidad a la historia de vida de los maestros Ordalha y Marlene, desde la "infamia" tratada por Michel Foucault. Investigación cualitativa con entrevistas realizadas en 2015. Los resultados apuntan a un legado que merece ser conocido por las nuevas generaciones de docentes.

Palabras clave: Resistance to teaching; life experience; foucaultian studies.

\section{Introdução}

Analisar o comportamento das mulheres na sociedade atual é entender o seu valor humano e perceber como estas foram silenciadas, oprimidas, excluídas e esquecidas pela sociedade desde à antiguidade, não importa seus feitos. Contar suas histórias é pensar que amanhã haverá outras, é entregar-se a uma análise detalhada a cada ponto dado no tecido "escrito", de forma transversal em que a linha possa atravessar e deixar marcas profundas, abocanhando os fiapos que saem dos pensamentos do pesquisador e misturando-se a outros ingredientes que vão formar a história de vida dessas mulheres numa leveza silenciosa para tirá-las do anonimato.

Desse modo, esse artigo tem o objetivo de apresentar a história de vida das professoras Ordalha de Araújo e Marlene Pedroso, bem como o poder de resistência ao exercício do magistério em localidades de difícil acesso do ex-Território Federal de Roraima. Para Marlene, somente a classificação nos três seletivos que fizera para professora não seriam suficientes para ser lotada nas escolas da capital, necessitava do poder político para abrir espaço o que não foi possível.

\footnotetext{
${ }^{1}$ Rede Estadual de Ensino de Roraima e Secretaria Municipal de Educação de Rorainópolis-RR.

${ }^{2}$ Inspirado na vida de minha mãe, uma costureira que aos 75 anos continua ativa em sua máquina, a qual faz seus modelitos uma verdadeira estilista.
} 
Já professora Ordalha foi envolvida por relações de poder decorrentes do convite do próprio governador Ottomar de Souza, que era amigo de sua família. Nesse percurso, foi a primeira Diretora Oficial da Escola de $1^{\circ}$ grau José de Alencar entre 1982-1988. A referida instituição foi implantada nas terras do Projeto de Assentamento Dirigido/ANAUÁ às margens da BR 174 sentido Roraima Manaus em 1981.

Professora Ordalha é lembrada com diferentes adjetivos, por exemplo, defensora dos alunos pobres, corajosa, honesta e, até ríspida. Pode ser retratada como uma mulher empoderada decidida pelo desenvolvimento da Educação na Amazônia roraimense entre as década de 19701980, uma vez que teve uma atuação, profissional, política e social bem intensa nesse período, quando lutou em defesa de melhores condições estruturais da escola José de Alencar, formação dos professores, e denunciou a realidade trágica dos migrantes por meio de seus ofícios dirigidos ao Governador Ottomar de Souza, como também aos Executores e engenheiros do Instituto Nacional de Colonização e Reforma Agrária (INCRA), Soldemar Nilo, Antônio Bezerra e Erasmo Lopes - Patrono da primeira turma de 8a série, em 1988.

A metodologia parte de uma pesquisa qualitativa, por meio de entrevistas semiestruturadas realizadas com Perla Araújo ${ }^{3}$, filha da professora Ordalha de Araújo Lima, e com a professora Marlene Pedroso ${ }^{4}$, em julho de 2015 em Boa Vista Capital de Roraima. Esse corpus foi necessário para conhecer a história da educação do Povoado Vila do Incra - atual município de Rorainópolis.

Como fundamentação teórica, pautamo-nos na obra de Michel Foucault "A vida dos homens infames" (2003), texto que inspirou o trabalho e nos fez comparar às "infames" retratados aqui como aquele sem fama, esquecido por seus atos heroicos, envolvidos pelas relações do poder político onde seus valores não são visíveis à sociedade.

\section{A vida dos homens infames}

Ao trazer à torna "A vida dos homens infames", no final da década de 1970, Michel Foucault nos privilegiou com uma bela literatura, destinada a provas sobre vidas silenciadas de pessoas sem nenhuma glória e que, por influência do exercício do poder, tornaram as vidas desses seres humanos mais desgraçados possíveis.

Foucault fornece imagens vivas e históricas ao leitor por meio dos arquivos exumados do internato do Hospital Geral e da Bastilha francesa, ou seja, manuscritos e documentos importantes que contavam as formas cruéis de como alguns seres humanos insignificantes, surgidos do meio dos mortos, foram excluídos da história por diversos motivos. Considerados imperdoáveis, no entanto, cada sujeito tinha uma história real, ações que os representavam perante a sociedade.

Foucault trabalhou intensamente debruçado sobre os arquivos, transformando-os em diversos projetos de pesquisa, e buscou mostrar o silêncio dos vencidos, que não deixaram marcas, histórias nem mesmo relatos de suas vidas desvalidas.

Eu quis que se tratasse sempre de existências reais; que se pudessem dar-lhes um lugar e uma data; que por trás desses nomes que não dizem mais nada, por trás dessas palavras rápidas e que bem podem ser, na maioria das vezes, falsas, mentirosas, injustas, exageradas, houvesse homens que viveram e estão mortos, sofrimentos, malvadezas, ciúmes, vociferações (FOUCAULT, 2003, p. 205).

\footnotetext{
${ }^{3}$ Perla Jordana Araújo de Lima, filha a professora Ordalha de Araújo de Lima, nascida em 24/10/1975. Endereço, Boa Vista-RR. Profissão: Assistente Administrativa entrevista em sua residência em 20/07/2015.

${ }^{4}$ Marlene da Silva Pedroso. Nascida em 06/08/1953 em Boa Vista-RR. Residente no município do Cantá - RR. Brasileira. Profissão: Professora do Quadro Federal. Local da entrevista: Praça do Garimpeiro Vista-Roraima. Horário da Entrevista: 7:20 min às 8:40min. Data: 05/07/2015.
} 
O filósofo relatou seus sentimentos ao encontrar documentos tão raros a respeito de vidas que ele considerou infames, em suas ações cotidianas, as quais suas expressividades não beneficiaram seus atos sufocados, "como se sufoca um grito, um fogo ou um animal por esganadura); procurei saber a razão pela qual se quis impedir com tanto zelo os pobres espíritos de passearem pelas estradas desconhecidas" (FOUCAULT, 2003, p. 204)

Assim como Foucault, dedicou-se a escrever a história de sujeitos infames apagadas pela história francesa, este artigo também traz a história de professoras esquecidas da história da educação roraimense as quais não são mencionadas as lutas dessas mulheres que deram a vida pela educação do PAD/ANAUÁ, uma luta que levou anos para que seus gritos fossem ouvidos e revelasse as premissas da educação de Rorainópolis.

\section{Uma pincelada pela trajetória de vida de professora Ordalha de Araújo}

Por esse ângulo, podemos construir os discursos daquela que em vida se chamou Ordalha Araújo de Lima, mulher empoderada, corajosa como filha, mãe, professora, amiga, diretora, supervisora e outras funções. Mulher que liderou entre 1982-1988 a escola de $1^{\circ}$ Grau José de Alencar com inúmeros desafios (infraestura, espaços de aprendizagem, moradia, transporte, água potável, mobiliário e professores sem formação no magistério). E durante oito anos não houve páreo para seu trabalho de liderar diversos grupo de pessoas, tornando-se uma das mulheres mais invejada do Assentamento Anauá, no meio político, social e educacional.

Ordalha nasceu em Boa Vista, Capital de Roraima, em 28 de fevereiro de 1954 e faleceu aos quarenta e sete anos de idade. Pouco tem sido lembrada como aquela que liderou a educação do assentamento Anauá/Vila do Incra e outras comunidades indigens do exTerritório Federal de Roraima.

Em entrevista, sua filha Perla Araújo recorda com carinho os feitos da mãe na região do assentamento:

Minha mãe faleceu em seu ambiente de trabalho. Era destemida, corajosa, com poder de decisão. Por causa de seu trabalho mudamos para muitos lugares difíceis de viver. Sem moradia e necessidades básica. Mais com isso aprendemos lições de compartilhar e não sermos egoístas. Sentir a dor do outro, do coitado que sofria por um pedaço de pão, uma roupa, um chinelo ou um medicamento. Ainda vejo minha mãe trabalhando até madrugada organizando eventos para angariar fundos em favor das escolas, dos alunos, das famílias doentes (Perla, 20/07/2015, grifos meus).

A filha descreve a mãe com os seguintes predicativos: "destemida”, "com coragem", "com o poder de decisão" e como alguém que tudo que planejava, conseguia. Contudo, a família pagava um preço que, segundo ela, era o sofrimento de morar em "lugares distantes, sem condições de moradia e necessidades básicas, mas aprendemos lições de compartilhar e não sermos egoístas, sentir a dor do outro, do coitado que sofria por um pedaço de pão, uma roupa, um chinelo, um medicamento".

A miséria estava presente nesses lugares, na migração característica dos nordestinos que fugiam da seca em busca das terras vazias de Roraima, e exercer o magistério naquele período se mostrava uma profissão de valor, decorrente da falta de profissionais na região, as vagas para as comunidades distantes (indígenas, fronteiras, ribeirinhas e assentamentos) eram ofertadas as pessoas que possuía de $4^{\mathrm{a}}$ a $8^{\mathrm{a}}$ série e tinham disponibilidade de desbravar a floresta roraimense.

Perla Araújo lembra as ações realizadas pela mãe, e mostra nostalgia ao dizer. "Ainda vejo minha mãe trabalhando até madrugada organizando eventos para angariar fundos em 
favor das escolas, dos alunos, das famílias doentes de malária". Nesse aspecto, o trabalho de professora Ordalha integra não somente o administrativo e o pedagógico, mas também ao social em busca do bem-estar dos migrantes e dos indígenas. O trabalho solidário fazia com empenho pela necessidade das pessoas que chegavam em situações de risco, e somente com a certeza de receber um pedaço de chão.

Ordalha conheceu e sentiu na pele a responsabilidade de assumir aos dezessete anos a carreira de professora e a necessidade dos alunos indígenas que seguiam nus, descalços, doentes pelo frio e falta de higiene. Nesse cenário, procurou compreender a forma de alimentar-se das crianças indígenas, cuidar da saúde dessas crianças e orientar às mães no cuidado diferenciado com seus bebês e as crianças pequenas, além de incentivar a frequentar a pré-escola. Buscou com avidez conhecimento e se fez conhecer pelo trabalho realizado, afinal seu futuro dependia exclusivamente de seu desempenho para vencer os desafios nas comunidades indígenas, que não foram poucos, e posteriormente na escola José de Alencar.

\section{A Escola José de Alencar um refúgio de isolamento e desafios nos confins de Roraima}

Depois de anos trabalhando em comunidades indígenas ao norte do ex-Território, Ordalha foi convidada pelo Governador Ottomar de Souza Pinto para trabalhar nos confins da Amazônia roraimense, aos vinte e oito anos de idade. Já experiente e sem escolha para um novo arcabouço, aceitou o trabalho pedagógico e administrativo da "Escolinha" do Povoado Vila do Incra5.

Ali, professora Ordalha se instalou às margens da BR 174, na casa de apoio do INCRA, onde parecia estar vivendo uma sucessão de desafios ao administrar a "Escolinha" com 104 alunos de $1^{\mathrm{a}}$ série para alfabetizar e somente três professoras para um total de 136 alunos. Possivelmente sentira-se desafiada ao procurar resolver os dilemas que envolveu sua estadia no território Waimiri Atroari': aceitação no trabalho, a ausência dos filhos, comunicação, moradia para as professoras que chegavam para trabalhar na escola, além do agenciamento de recursos financeiros da instituição. Não havia supermercados, hospitais, praças, bibliotecas, livrarias, coisas que poderiam fazer diferença nas relações sociais, coletivas e individuais dos migrantes.

Por sua vez na capa do livro de frequência dos professores, Ordalha escreveu:

Sinto-me como um vendaval, prestes a levar tudo pela sua força, me sinto angustiada, mas busco forças nestas palavras. "O senhor é meu pastor, nada me faltará". Sei que tem crescido os meus adversários, mas não me deixa sucumbir, lava minhas incertezas nas águas correntes de tua misericórdia, não permitas que as frustações, as mágoas, o egoísmo e, sobretudo a inveja faça parte de minha vida (ARAÚJO, março de 1987).

Diante das lutas, possivelmente professora Ordalha sentia-se ameaçada, talvez em função daqueles contrário à sua administração e até pelo desejo de também liderarem a escola. $\mathrm{Na}$ verdade, sua colega Marlene Pedroso acrescentou: "o uso da diplomacia garantiu as relações de poder que envolvia o trabalho da Ordalha. "Onde me mandares, irei".

Professora Ordalha, ora obedecia cegamente as ordens do Brigadeiro Ottomar e outros governos, mas também desobedecia abertamente quando as ordens não lhe convinham defendendo seu ponto de vista a respeito das tomadas de decisões sobre o bom andamento da

\footnotetext{
${ }^{5}$ Incra pelo fato da Sede Avançada do INCRA está localizada nesse povoado fundado por migrantes nordestinos. ${ }^{6}$ Etnia indígena pertencente a quem às terras do povoado Vila do Incra na divisa de Roraima com o Amazonas atual Distrito de Jundiá às margens da BR 174.
} 
instituição, construção dos anexos para atender a demanda que crescia a cada ano, a insistência na construção de casa de apoio para as professoras e implantação de novas séries.

Sua felicidade estava no trabalho escolar, não importava a quem atendia: se mulher, negro, pobre, índio, religiosos, migrantes; seu interesse estava acima dos desafios, afinal eram reais as dificuldades que eles enfrentavam nesse lugar distante de tudo. E conforme afirma Foucault (2003, p. 203), sobre as "vidas singulares tomadas por não sei quais acasos, estranhos poemas, eis o que eu quis juntar em uma espécie de herbário". E neste vai e vem de ideias, sua "história de vida profissional" permaneceu em silêncio nos rincões desses lugares ainda desconhecidos do restante desse Brasil.

Professora Ordalha sentia-se impotente diante das salas lotadas de crianças e adolescentes, sem carteiras para sentar, sem livros, registros de nascimento para realizar a matrícula, armários, depósito para armazenar os alimentos, biblioteca, fogão a gás, água encanada... Um dos dilema que logo procurou resolver com a colaboração das famílias foi a construção dos bancos e mesas com madeira da derrubada das matas do vilareja. Também, se empenhou em providenciar meios e recursos para os pais adquirir o registro de nascimento dos filhos, para que pudessem frequentar a escola regularmente.

Enfim, a perspectiva de vida dessa educadora infame "[...] A rapidez do relato e a realidade dos acontecimentos relatados; [...] nesses textos, a condensação das coisas ditas, que não se sabe se a intensidade que os atravessa deve-se ao clamor das palavras ou à violência dos fatos que neles se encontram" (FOUCAULT, 2003, p. 203).

Diante do exposto, fica evidente que somente a pesquisa ${ }^{7}$ foi capaz de construir as pegadas pedagógicas dessa mulher e mostrar sua caminhada pela educação, um legado que deixou às novas gerações de educadores de Roraima. Professora Ordalha encerrou a carreira como Supervisora da escola Voltaire Pinto Ribeiro em Boa Vista Capital, e ali tombou pela morte causada por um Acidente Vascular Cerebral (AVC), em 6 de agosto de $2001 \mathrm{em}$ pleno exercício da função. Mas antes fez história, e por três décadas trabalhou incansável pela educação de Roraima.

\section{Professora Marlene e sua resistência ao magistério na escola do Assentamento Anauá}

A história da professora Marlene Pedroso mescla-se com a história de vida profissional de professora Ordalha sua contemporânea na educação do Assentamento Anauá. Professora Marlene relata os estilhaços e memórias de uma vida infame que estava condicionada às responsabilidades domésticas quando ainda criança; não obstante, suas memórias revelam reflexões históricas de uma vida fastidiosa pelo trabalho, contudo, não se deixou abater, lutou pelo trabalho de professora na capital Boa Vista por anos até alçar seus objetivos quando fora transferida para trabalhar na capital dos sonhos.

Já adulta recusou-se a exercer o magistério na escola dos distintos cidadãos da região do Assentamento Anauá e a escola da maloca do Surrão. Foi atravessada por relações de poder em seus discursos, quando se recusava a trabalhar em lugares distantes e deixar sua família. Em seus discursos apresenta as dificuldades de aceitação pelas precárias condições de trabalho, saúde, lazer e moradia nas respectivas localidades. Não se achava preparada para trabalhar longe da família, enfrentar os desafios do transporte, falta de energia elétrica, água potável dentre tantos outros.

Assim, as relações de poder se fizeram presente antes e depois de sua jornada docente.

\footnotetext{
${ }^{7}$ Pesquisa iniciada no Mestrado: "Memórias dos pioneiros do projeto de assentamento dirigido Coronel Salustiano e Anauá: A Casa - Escola do Valentin Rorainópolis-RR- (1975-1982)” e melhor desenvolvida durante a pesquisa do doutorado, "Dizeres de (in)fâmia: história(s) da Escola José de Alencar -navegando pelas águas do rio Anauá, baixo rio Branco, Roraima, 1959-1982” em que foi possível aprofundar em sua história de vida e profissional.
} 
Em outras palavras [...] o poder não existe; existem sim práticas ou relações de poder. O que significa dizer que o poder é algo que exerce, que se efetua, que funciona. E que funciona como uma maquinaria, como uma máquina social que não está situada em nenhum lugar privilegiado ou exclusivo, mas se dissemina por toda estrutura social. Não é um objeto, uma coisa, mas uma relação (MACHADO, 1979, p. XVI).

Esse poder, permeou as decisões da professora Marlene, seu desejo de ser professora foi transformado e moldado quando o Colégio Euclides da Cunha a preparou para outras atividades da vida: auxiliar de enfermagem, cuidadora de idosos e recepcionista. Militante, como filha da terra, buscava no estudo prioridade, no sentido de formação profissional e estabilização financeira. Sua luta pelo magistério compreende uma vida infame, sem que tivesse a quem recorrer politicamente pelo direito de escolher o lugar para exercer à docência. A resistência durou anos até perceber que estava perdendo espaço, corria o risco de perder de vez a oportunidade de trabalhar na profissão que desejou desde criança: "[...] o poder que espreitava essas vidas, que as perseguiu, que prestou atenção, ainda que por um instante, em suas queixas e em seu pequeno tumulto, e que as marcou com suas garras" (FOUCAULT, 2003, p. 206).

O poder de escolha lhe foi negado, e após trabalhar em diferentes lugares à espera da chamada para lecionar na capital, finalmente aceitou sua lotação na Escola José de Alencar, em fevereiro de 1982. Sua resistência era pertinente, não desejava trabalhar longe de sua família, sentia-se responsável pelos irmãos(as) desde os dez anos de idade. Ao relatar sua experiência, afirma ter enfrentado os desafios com os pés no chão, tendo em mente o combustível necessário para direcionar seus pensamentos revoltos, escondidos pelas portas da escola, assumindo o limite de suas forças, diligência e habilidades para lidar com os desafios da floresta, dormir na sala de aula com a família por falta de moradia, além de enfrentar os animais selvagens e sala de aula lotada.

O poder está diretamente a olhar para as microrrelações sociais que envolvem os diferentes poderes dos governos, dos poderosos e suas normas governamentais na sociedade moderna, constituindo-se de base jurídica por meio de mecanismos que geram o controle do Estado, nação ou instituição.

Trata-se [...] de captar o poder em suas extremidades, lá onde ele se torna capilar; captar o poder nas suas formas e instituições mais regionais e locais, principalmente no ponto em que, ultrapassando as regras de direito que o organizam e delimitam, ele se prolonga, penetra em instituições, corporificase em técnicas e se mune de instrumentos de intervenção material, eventualmente violentos (FOUCAULT, 1979, p. 182).

Assim, o poder na visão de Foucault tende, sobretudo, a produzir efeitos constituídos do saber e da verdade, e, para tanto, nos instiga a interrogar, refletir, registrar ideias, propor melhorias que possam efetuar uma reflexão histórica, considerando a compreensão da interpretação do poder a partir da hermenêutica e do saber histórico, que além de produzir saber, busca produzir riquezas, de forma que o direito ao saber seja compreendido como procedimentos das relações captadas pelo poder e de ações desenvolvidas pelos sujeitos que nele atuam.

$\mathrm{Na}$ escola José de Alencar (Escolinha), professora Marlene exercia o poder empunhando suas armas em defesa dos alunos pelo apoio moral, psicológico, econômico e social para viver na floresta, isolada de outras culturas e de necessidades básicas a sobrevivência humana. Uma experiência real, e ao ser entrevistada revela suas aflições e os motivos de tanta resistência. 
[...] Como aluna do Colégio Euclides da Cunha, tive o privilégio de ser convidada pelo Coordenador da Educação do Interior, o professor Paulo Lopes, para trabalhar nas escolas: do Itã, do Surrão e Assentamento Anauá. Não aceitei o convite, o desafio era grande, ficava longe, muita malária. [...]. Boa-vistense pensava em trabalhar perto de minha família e não morar nesse fim de mundo com filho pequeno sem casa e transporte. [...] Esse lugar não me interessava. Depois de pensar e trabalhar em muitos lugares, as necessidades me fizeram recuar. Aceitei ser professora onde eu nunca quis. Uma experiência cheia de questões políticas, uma escola sem espaço para tanto aluno, salas cheias, crianças que não sabiam ler nem escrever. As dificuldades foram muitas, e não era qualquer pessoa que estava preparada para enfrentar os interiores de Roraima. Os barracos, cozinhar lenha e morar com os animais selvagens, andar de canoa nos rios e conviver com os índios! Eu não tinha que aceitar isso! [...] Mas escolhi a melhor localidade mesmo longe (MARLENE PEDROSO, 05/07/2015, grifos meus).

Professora Marlene garante que teve "o privilégio de ser convidada pelo Coordenador da Educação do Interior, o professor Paulo Lopes, para trabalhar nas escolas: do Itã, do Surrão e Assentamento Anauá”. Porém, recusou os convites já naturalizados, na esperança de facilitar a organização de sua vida familiar e financeira que, de certa forma, estavam no mesmo lugar que lhe exigia determinação e cuidado de si mesma e seus familiares.

Após analisar as oportunidades, "Não aceitei o convite, o desafio era grande, ficava longe, muita malária [...] "Boa-vistense, pensava em trabalhar perto de minha família e não morar nesse fim de mundo com filho pequeno sem casa e transporte". Em seus discursos, a Vila do Incra se mostrava um campo de guerra, um grande obstáculo que "não lhe interessava".

Marlene Pedroso deixa claro sua resistência a oferta de emprego em escolas isoladas, um dos motivos grande incidência de "malária", embora tenha se considerado privilegiada por ser convidada pelo "Coordenador". No entanto, a colaboradora se ver perdendo as oportunidades de exercer o magistério, por um capricho, e entender que era capaz de lecionar em qualquer etapa da educação básica mesmo sem a devida formação.

Mas uma vez, professor Paulo Lopes a convida possivelmente pela carência de professores para a região. Um conjunto de ações leva Marlene a aceitar a oferta pelo temor de perder de vez o ingressar ao magistério. "Aceitei ser professora onde eu nunca quis". Contra sua vontade foi enviada para lecionar no primeiro semestre de 1982 , na turma de $1^{\mathrm{a}}$ e $2^{\mathrm{a}}$ série, na administração da professora Adalgiza Xavier, a precursora da educação do povoado Vila do Incra. Professora Marlene permaneceu por sete anos, dos quais quatro trabalhando como professora de matemático de $5^{\mathrm{a}}$ a $8^{\mathrm{a}}$ série do ensino fundamental da Escola José de Alencar.

Diante da resistência, afirma "e não era qualquer pessoa que estava preparada para enfrentar os interiores de Roraima, os barracos, cozinhar a lenha e morar com os animais selvagens, anda de canoa, conviver com os índios". Os discursos da professora Marlene estão entremeados de surpresas, rejeições, ordens, dúvidas, medo e insegurança em viver na selva amazônica.

Em sua opinião, as relações de poder se constituem, não somente pelo Governador Ottomar de Souza Pinto, mas também o poder que circulava e atingia de certa forma a escola José de Alencar, pela exigência do trabalho, de maneira a domesticá-los e produzir aprendizagem sem que houvesse o controle do cansaço, espaços adequados de trabalho, ferramentas, mobiliário e controle de turma.

Era muito complicado o trabalho de 40 horas, em situações de caos naquele pequeno espaço com 35 a 40 alunos. Também quando falava no Ottomar que sempre chegava de surpresa nas escolas com sua comitiva, as pessoas não 
encaravam esse trabalho com felicidade. Ottomar fiscalizava de perto o trabalho dos diretores, professores e até os alunos ele fazia o teste de leitura, de matemática e educação Moral e Cívica (MARLENE PEDROSO, 05/07/2015, grifos meus).

Professora Marlene lembra das dificuldades sobre "o trabalho de 40 horas, em uma situação de caos naquele pequeno espaço com 35 a 40 alunos", ainda que fosse feito um juramento solene quando assinavam o contrato de trabalho. Os termos usados acima demonstram como era trabalhar nessa escola em plena ditadura militar: $\mathrm{O}$ "caos" se justifica pelo trabalho em dois turnos, "pequeno espaço", as turmas lotadas nos cubículos, no pátio da escola, tonando-se um desafio às docentes pela exigência da direção e da família no aprendizado dos filhos.

A análise do excerto, fornece detalhes sobre as visitas do Governador Ottomar, sujeito emblemático ao trabalho pedagógico: pegos de surpresa "as pessoas não encaravam esse trabalho com felicidade [...] Ottomar fiscalizava de perto o trabalho dos diretores, professores e até os alunos", ele "causava medo". O governador Ottomar de Souza, exigia o trabalho pedagógico com o desenvolvimento dos alunos na leitura, cálculos matemáticos, escrita e civismo.

Todos esses desafios, trouxeram experiência, vivência e transformação como pessoa, ao ser enviada para trabalhar na Escola de $1^{\circ}$ Grau José de Alencar. Marlene percebe seu papel de educadora, o valor da empatia, do cuidado, e a felicidade dos alunos. A experiência de desbravar o espaço, trabalhar em condições adversas, cuidar dos alunos, são realidades que vão além da sala de aula, ao proteger os alunos dos animais selvagens e peçonhentos, construir hortas e contribuir com a merenda escolar.

Nesse sentido, os infames dessa história se destacam pela persistência na realização das distintas atividades da escola.

Não é uma compilação de retratos que se lerá aqui: são armadilhas, armas, gritos, gestos, atitudes, astúcias, intrigas cujas palavras foram os instrumentos. Vidas reais foram 'desempenhadas' nestas poucas frases; não quero dizer com isso que elas ali foram figuradas, mas que, de fato, sua liberdade, sua infelicidade, com frequência sua morte, em todo caso seu destino foram, ali, ao menos em parte, decididos (FOUCAULT, 2003, p. 206).

Desse ponto de vista, é notório a relevância do texto "A vida dos homens infame" para definir as relações de poder que permeiam as vidas dessas mulheres que trazem a ideia de força, obrigação e não de liberdade de escolha da instituição e lugar de trabalho. O texto nos oportuniza aprendermos a ouvir os discursos sobre o poder que afetaram essas vidas, e compreender as ações daquelas que por trás dos bastidores contribuíram para a construção da História da Educação de Rorainópolis.

Ainda com relação ao poder:

$\mathrm{Na}$ oficina, na escola, no exército funciona como repressora toda uma micropenalidade do tempo (atrasos, ausências, interrupções das tarefas), [...] Ao mesmo tempo é utilizada, a título de punição, toda uma série de processos úteis, e vão do castigo físico leve a privações ligeiras e a pequenas humilhações. Trata-se ao mesmo tempo de tornar penalizáveis as frações mais tênues da conduta, e de dar uma função punitiva aos elementos aparentemente indiferentes do aparelho disciplinar (FOUCAULT, 2013, p. 171).

Esse poder, conduzia as professoras da Escola de $1^{\circ}$ Grau José de Alencar, a puxar água do poço para consumo dos estudantes, cozinha a lenha, pilar o arroz, usar a lamparina para 
iluminar a escuridão da noite. Tudo isso é marcado pelo esquecimento da História da Educação estadual, regional e local, quando as ações dessas mulheres passam pelo crivo das responsabilidades e não deixam que suas memórias sejam esfareladas, mas, que as lembranças de suas experiências de vida profissional enriqueça a alma de outros professores, e possam então valorizar a luta pessoal, política, social e cultural dessas guerreiras numa época de ouro refinado em relação a oportunidade de ingresso ao magistério no ex-Território de Roraima.

\section{Considerações}

Este artigo teve como proposta dar visibilidade à história de vida dessas mulheres que sabiam lidar com os conflitos que permeavam a educação da escola do Asentamento Anauá. Para tal, promoviam eventos festivos e esportivos para integrar os migrantes que lutavam por terra, escolas, moradia e saúde. Essas professoras não ousavam pronunciar a palavra "não posso", e assim, atuaram em escolas isoladas de forma produtiva e contribuiram para o desenvolvimento da educação regional e local.

Os resultados apontam para a pouca experiência profissional da professora Marlene, aliada à quantidade de crianças e as míseras condições do espaço de trabalho. A pesquisa, também apresentou diversos traços de empoderamento das colaboradoras, ao resistirem ao poder político militar de uma época, quando professora Ordalha ao gerenciar escolas públicas buscava autonomia, formação dos professores, sujeitos ativos que dependiam do magistério para permanecer na escola José de Alencar e prover as necessidades de suas famílias. Satisfeitos ou não, a escola desenvolveuse e caminhou pelo trabalho incansável daquele grupo gestado pela professora Ordalha de Araújo.

Professora Marlene ao contrário da professora Ordalha, mostra sua resistência em trabalhar em comunidades isoladas por diferentes motivos, entre eles a malária, uma doença transmitida pelo mosquito Anopheles, um dos inúmeros motivos que a fez recusar as ofertas de trabalho, contrapondo-a às relações de poder do regime militar que governava o país, pois em Roraima, muito antes da ditadura, já era governada por militares, consequentemente a obrigaritoridade de cumprir ordens sem contestar fazia parte da cultura de seus habitantes.

Embora tais profissionais não sejam heroínas, mártires, santas, mas, deixaram um legado que merece ser conhecido pelas novas gerações de professores e alunos desse lugar. Professoras que mostram algo valioso, histórico que não está presente nas memórias do Assentamento Anauá, no Arquivo Público de Roraima ou nos passos memoriais da Educação Estadual de Roraima. São histórias verídicas e inconfessáveis verdades de mulheres empoderadas da educação de Rorainópolis, capazes de transpor barreiras e mesmo sem saber realizavam um trabalho colaborativo.

\section{Referências}

ARAÚJO, O. Livro de frequência dos professores. 1987.

FOUCAULT, M. Soberania e disciplina. In: MACHADO, R. (Org.) (Trad.). Microfísica do poder. 8. ed. Rio de Janeiro: Graal, 1979. p. 179-191.

FOUCAULT, M. A vida dos homens infames. In: MOTA, M. B. (Org.). Ditos e escritos IV: estratégia, poder-saber. Rio de Janeiro: Forense Universitária, 2003. p. 203-222,

FOUCAULT, M. Vigiar e punir: nascimento da prisão. Trad. R. Ramalhete. 41. ed. Petrópolis: Vozes, 2013. 
MACHADO, R. Introdução: por uma genealogia do poder. In: MACHADO, R. (Org.) (Trad.). Microfísica do poder. 8. ed. Rio de Janeiro: Graal, 1979. p. VII-XXIII.

\section{Sobre a autora}

Maria Clelia Pereira da Costa. Maria Clelia Pereira da Costa nasceu e viveu até os treze anos de idade na Floresta Acreana, na região de Valparaíso, Humaitá, atual município de Porto Walter, na localidade de Terra Preta... Filha de soldado da borracha o senhor Manoel da Costa e de Nazira Pereira, aprendeu muito sedo a conviver com os recursos da floresta, e usar as folhas das árvores como papel e os espinhos de taboca como lápis para escrever. Ao longo de sua caminhada muito lutou para chegar até aqui. Atravessou fronteiras, a exclusão da escola em função da pobreza, racismo e questões sociais. Pela resiliência hoje é Professora Efetiva da Rede Estadual de Ensino do Estado de Roraima desde 1991. Supervisora Pedagógica Efetiva da Secretaria Municipal de Educação de Rorainópolis, atuando nas escolas da rede entre 2002-2013. Em 2021 tem trabalhado para construir a proposta Pedagógica da Educação Infantil da Rede Municipal de Rorainópolis. É graduada em Pedagogia, pela Universidade Federal de Roraima-UFRR (2001). Pós-Graduada em Educação Interdisciplinar pelo Instituto Cuiabana de Educação-MT (2003), Especialista em Gestão Escolar-UFRR (2010) e Especialista em Educação Infantil UFRR (2012). Mestra em Educação, título conferido pela Universidade São Francisco-USF Campus Itatiba-SP pela defesa da Dissertação em 15-02-2016, cujo título é: Memórias dos pioneiros do projeto de assentamento dirigido Coronel Salustiano e Anauá: A Casa - Escola do Valentin Rorainópolis - RR (1975-1982. Doutora em Educação pela Universidade São Francisco-USF Campus Itatiba-SP Tese defendida em novembro de 2020, cujo título é: dizeres de (in)fâmia: história(s) da Escola José de Alencar - navegando pelas águas do rio Anauá, baixo rio Branco, Roraima, 1959-1982. Integrante do Grupo de pesquisa foucaultiana da USF.

E-mail: cleliasup@gmail.com. 